\title{
Should the Management of Embolic Stroke in the Elderly Be Changed if They Also Have COVID-19?
}

\author{
Carolina Seabra, Bárbara Silva, Vítor Fagundes, João Rocha, Luís Nogueira, Mari Mesquita \\ Centro Hospitalar Tâmega e Sousa, Penafiel, Portugal
}

Doi: 10.12890/2020_001736 - European Journal of Case Reports in Internal Medicine - ㄷ EFIM 2020

Received: 19/05/2020

Accepted: 21/05/2020

Published: 25/05/2020

How to cite this article: Seabra C, Silva B, Fagundes V, Rocha J, Nogueira L, Mesquita M. Should the management of embolic stroke in the elderly be changed if they also have COVID-19? EJCRIM 2020;7: doi:10.12890/2020_001736.

Conflicts of Interests: The Authors declare that there are no competing interests.

This article is licensed under a Commons Attribution Non-Commercial 4.0 License

\section{ABSTRACT}

Introduction: A strong association between stroke and atrial fibrillation (AF) has been demonstrated. Anticoagulation for the prevention of stroke in high-risk patients has the benefit of improving the life expectancy, quality of life, autonomy and social functioning of the patient. The COVID-19 pandemic poses challenges for stroke patients because of the association between SARS-CoV-2 infection and thromboembolic risk.

Case description: We describe the case of an 84-year-old female patient admitted due to an embolic stroke and non-anticoagulated AF. Her admission symptoms were sensory-motor aphasia and severe right limb paresis with an NIHSS score of 24. The diagnosis of embolic stroke (namely, total anterior circulation infarct; TACI) was made. Her stroke was extensive so she was not started on anticoagulation. During hospitalization, new embolic events occurred and a concomitant diagnosis of COVID-19 was made with progressive respiratory dysfunction followed by multiorgan failure. The patient died despite appropriate treatment.

Discussion: The prognosis of elderly patients with cardioembolic stroke depends on anticoagulation administration. The NIHSS score on admission of our patient meant anticoagulation therapy was not appropriate. The diagnosis of COVID-19 contributed to the patient's death.

\section{LEARNING POINTS}

- Anticoagulation should be considered in stroke patients with total infarction and atrial fibrillation.

- There is an association between COVID-19 and thromboembolic stroke.

- $\quad$ Elderly patients with stroke and COVID-19 are at higher risk of death.

\section{KEYWORDS}

Embolism, stroke, COVID-19, atrial fibrillation

\section{INTRODUCTION}

A strong association between stroke and atrial fibrillation (AF) has been demonstrated. Anticoagulation for the prevention of stroke in highrisk patients has the benefit of improving the life expectancy, quality of life, autonomy and social functioning of the patient ${ }^{[1]}$. In the last few decades, dysrhythmia has been identified as the main cause of thromboembolism in stroke patients ${ }^{[2]}$. The development of AF results in contractile dysfunction and stasis, which increases the risk of thromboembolism ${ }^{[2]}$. At the same time, systemic risk factors increase the risk of stroke through other atrium-independent mechanisms ${ }^{[2]}$.

In December 2019, there was an outbreak of a new coronavirus (SARS-CoV-2) in China, which developed into an unprecedented global public health crisis presenting an increased risk of stroke in patients through an association between COVID-19 and thromboembolic risk ${ }^{[3]}$. 
Many patients with acute respiratory distress syndrome (ARDS) secondary to COVID-19 have developed life-threatening thrombotic complications $^{[3]}$.

In this article, we describe the case of a patient hospitalized with embolic stroke and respiratory distress whose test for SARS-CoV-2 was negative on admission. During hospitalization, she experienced new cerebral embolic events and was also diagnosed with COVID-19.

\section{CASE DESCRIPTION}

On 11 April 2020, an 84-year-old patient, who had a prestroke functional ability of 0 on the modified Rankin scale, attended the emergency department due to sudden onset sensory-motor aphasia and severe right limb paresis. She also had signs of respiratory distress and desaturation with an $\mathrm{SpO}_{2}$ of $80 \%$. Her medical history included vascular risk factors such as hypertension and obesity. Despite having a known cardiac arrhythmia, she was not on anticoagulation therapy.

On admission, her blood pressure (BP) was 183/93 mmHg, heart rate (HR) was $88 \mathrm{bpm}$ and the electrocardiogram (EKG) showed an AF rhythm without acute signs of ischaemia. Her neurological examination revealed she was drowsy but opened her eyes to speech, had global aphasia, eye deviation to the left, apparent right homonymous hemianopsia, right hemiplegia, and right extensor plantar reflex. Her NIHSS score was 24 (scores range from 0 to 42, with higher numbers indicating greater stroke severity).

Brain computed tomography (CT) showed no acute signs of ischaemia or haemorrhage (Fig. 1), while CT angiography showed no evidence of large vessel occlusion. It was not possible to identify the time of symptom onset and therefore there was no indication for intervention with thrombolysis or thrombectomy. A total infarction was assumed and so anticoagulation therapy was not initiated.
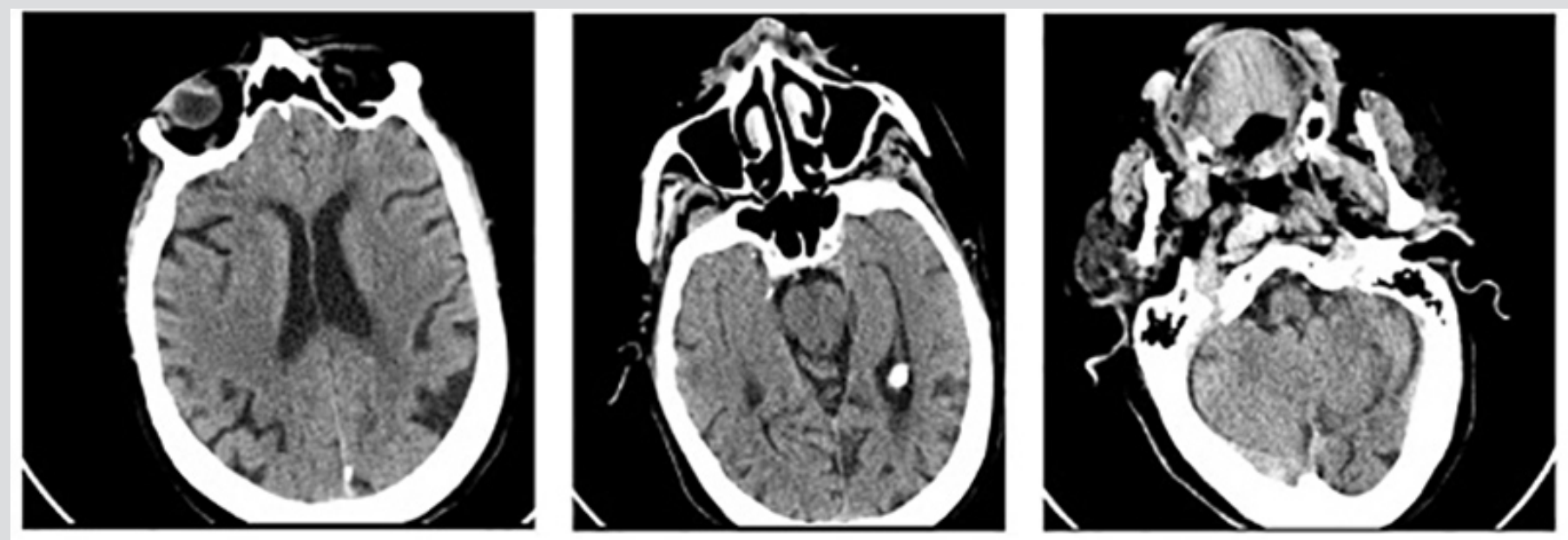

Figure 1. Cerebral CT scan on admission does not reveal any acute lesions
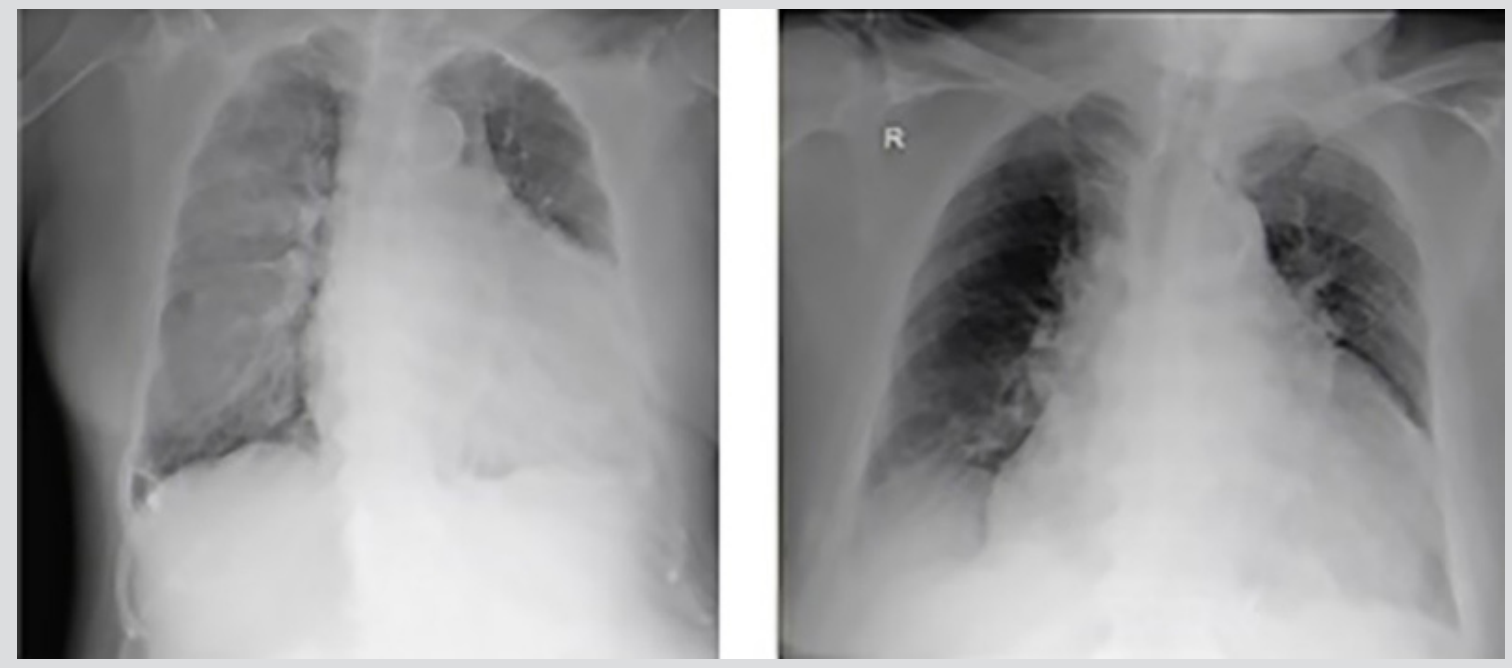

Figure 2. Chest radiographs, on admission (left) and after worsening (right) 
A SARS-CoV-2 test was performed because of respiratory distress, but was negative, while a chest $\mathrm{x}$-ray revealed cardiomegaly with no other changes (Fig. 2, left).

The patient was hospitalized with total infarction of the left middle cerebral artery (TACl, total anterior circulation infarct) according to the OSCP classification, and probable aspiration pneumonia for which she had been started on antibiotics.

A 24-hour EKG recording revealed atrial flutter throughout the entire recording. Carotid and vertebral echo Doppler ultrasound was only relevant for $>50 \%$ stenosis of the right external carotid artery. Transthoracic echocardiography did not reveal the source of the thrombus. Blood tests showed: uric acid $4.8 \mathrm{mg} / \mathrm{dl}$, total cholesterol $179 \mathrm{mg} / \mathrm{dl}, \mathrm{HDL} 42 \mathrm{mg} / \mathrm{dl}$ and LDL $112 \mathrm{mg} / \mathrm{dl}$, triglycerides $123 \mathrm{mg} / \mathrm{dl}, \mathrm{HbA} 1 \mathrm{C}$ $6.2 \%$, TSH $0.35 \mu \mathrm{lU} / \mathrm{ml}$, T4Free $1.44 \mathrm{ng} / \mathrm{dl}$ and T3Free $3.27 \mathrm{pg} / \mathrm{ml}$ (Table 1). The complete blood count, prothrombin time and partial thromboplastin time were normal.

On 22 April, the patient's general condition deteriorated with new neurological deficits and a need for increased oxygen supplementation. The chest $\mathrm{x}$-ray was repeated and showed radiological deterioration, with diffuse bilateral infiltrates of peripheral predominance and erasure of the right costophrenic sinus (Fig. 2, right). On the same day, a control computed tomography (CT) scan of the brain showed slight bleeding (Fig. 3), while magnetic resonance imaging (MRI) of the brain confirmed recent embolic lesions in the middle cerebral artery territory and in the vertebrobasilar territory (Fig. 4).

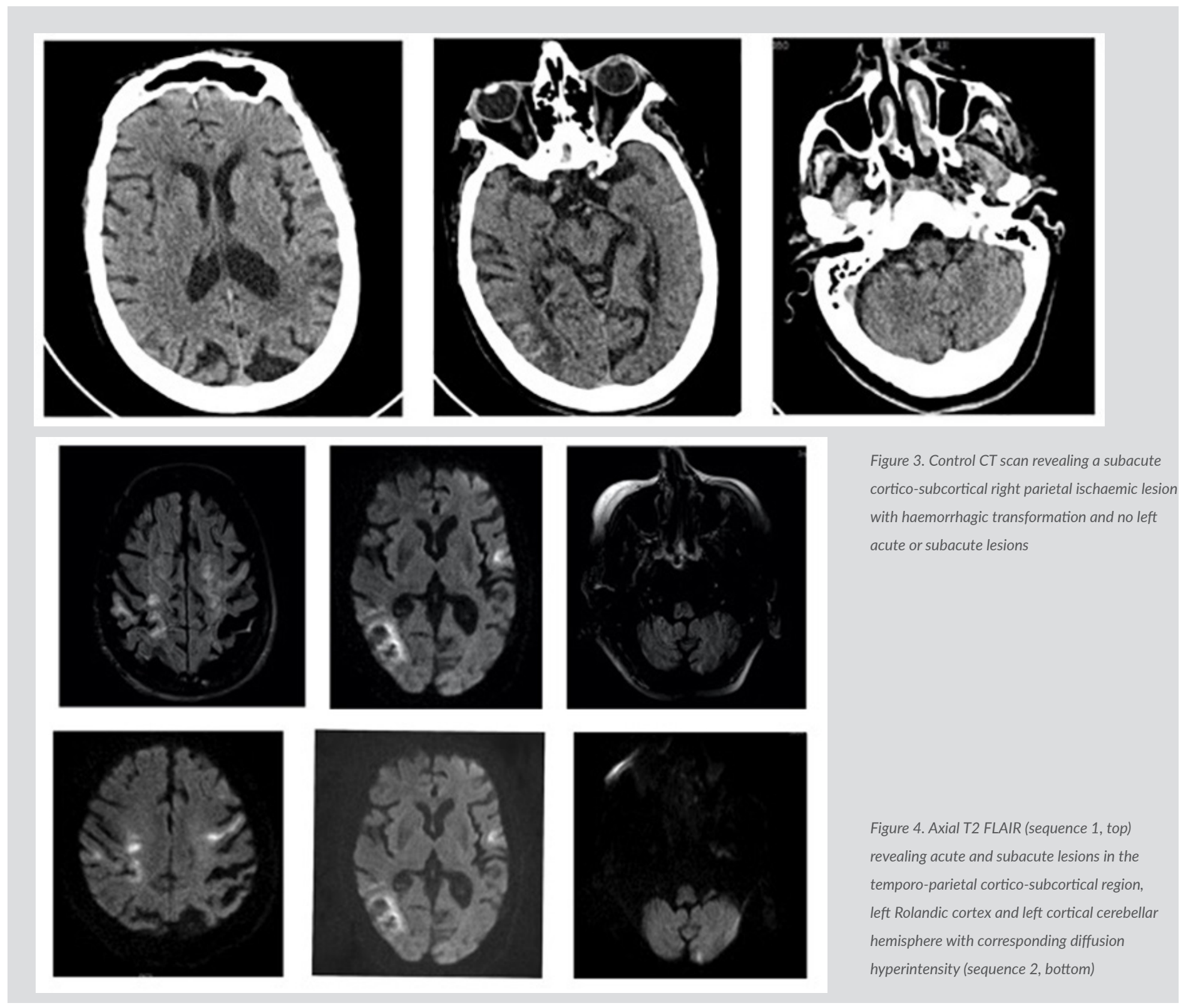


Given the numerous territories involved, with cortico-subcortical acute lesions but no significant large vessel disease, an embolic source was strongly suspected.

A new SARS-CoV-2 test was conducted and was positive for COVID-19. Patchy ground-glass opacities in bilateral lung apices were seen on chest CT, while chest CT angiography excluded pulmonary thromboembolism (Fig. 5).
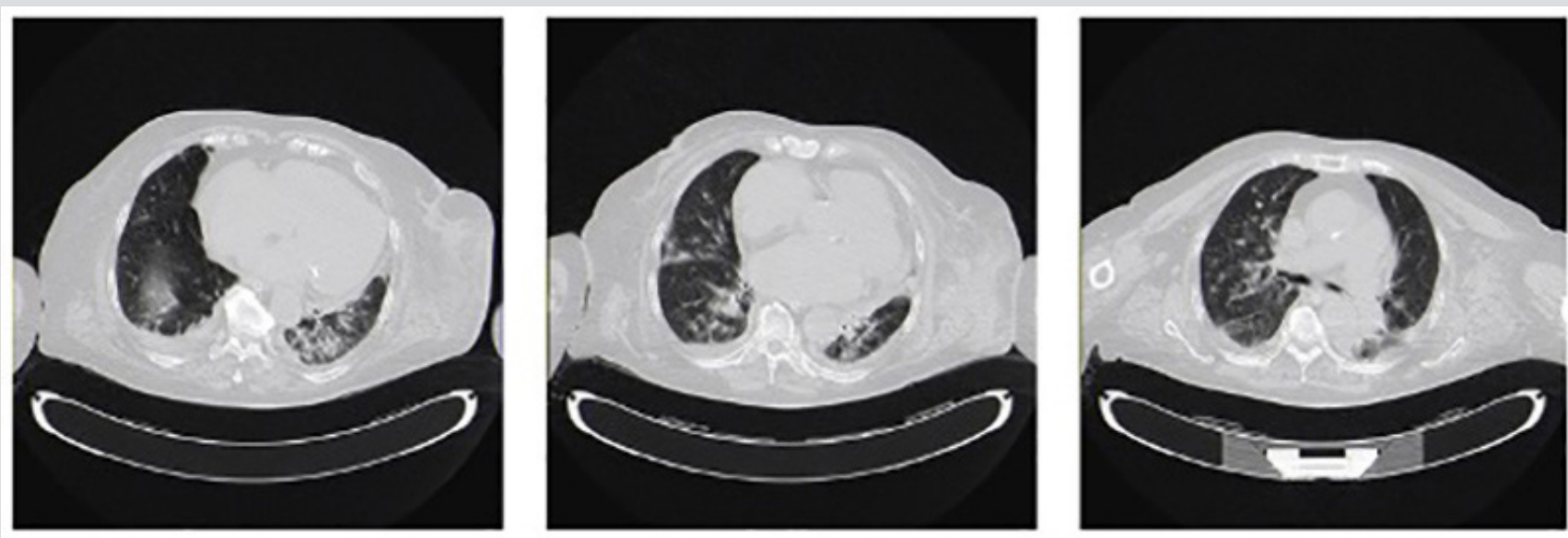

Figure 5. CT of the chest demonstrating patchy ground-glass opacities in bilateral lung apices, characteristic for atypical pneumonia in COVID-19

The patient was transferred to the COVID-19 ward, where she developed worsening renal dysfunction (Table 1) and oligoanuria which did not respond to medical treatment. The patient died on 3 May.

\section{DISCUSSION}

The management of treatable risk factors and common mechanisms of brain ischaemia is important for reducing the risk of ischaemic stroke. For patients with ischaemic stroke who have atrial fibrillation, oral anticoagulation is recommended for secondary stroke prevention ${ }^{[1]}$. Based mainly on expert consensus, the timing of anticoagulation initiation for patients with an appropriate indication is mainly dependent on the size of the acute infarct and the presence of factors such as symptomatic haemorrhagic transformation ${ }^{[1]}$.

Brain imaging should be conducted before anticoagulation initiation to confirm the absence of intracranial haemorrhage and to assess the extent of cerebral infarction. The size of the infarct is presumed to correlate with the risk of haemorrhagic transformation and determines the impact of the timing of anticoagulant initiation. Clinical estimation of infarct size may be improved by using validated scales that have been correlated with infarct volume and clinical outcome, such as the National Institutes of Health Stroke Scale (NIHSS).

Our patient had an NIHSS of 24 in light of which, according to the European Society of Cardiology and European Heart Rhythm Association recommendations, acute phase anticoagulation was not advised. Coagulopathy and vascular endothelial dysfunction have been proposed as complications of COVID-19 [4]. Therefore, the current guidelines might need to be reviewed in COVID-19 patients.

Although the pathophysiology underlying severe COVID-19 remains poorly understood, COVID-19 may predispose to both venous and arterial thromboembolism due to excessive inflammation, hypoxia, immobilization and diffuse intravascular coagulation ${ }^{[3]}$.

Stroke is the major cause of long-term disability in adults, and the second leading cause of death worldwide. Mortality from COVID-19 seems relatively low and appears driven by the presence of severe ARDS. There are no data yet regarding mortality and the association between embolic stroke and COVID-19.

Management is challenging due to the acuity of the illness and a paucity of high-quality evidence regarding the efficacy and safety of different approaches to prevent or treat thromboembolic complications of the disease.

In the case we describe, SARS-CoV-2 infection contributed to the death of our patient. This case provides additional evidence of the thrombotic risk in patients with COVID-19.

The association between large-vessel stroke and COVID-19 requires further investigation. 


\begin{tabular}{|c|c|c|c|c|c|c|c|c|}
\hline \multirow[t]{2}{*}{ Variable } & \multirow[t]{2}{*}{$\begin{array}{c}\text { Reference } \\
\text { range }\end{array}$} & \multirow[t]{2}{*}{$\begin{array}{c}\text { On } \\
\text { admission }\end{array}$} & \multicolumn{6}{|c|}{ Hospital day (date) } \\
\hline & & & $\begin{array}{c}7 \\
(17 / 04)\end{array}$ & $\begin{array}{c}12 \\
(22 / 04)\end{array}$ & $\begin{array}{c}15 \\
(25 / 04)\end{array}$ & $\begin{array}{c}17 \\
(27 / 04)\end{array}$ & $\begin{array}{c}18 \\
(28 / 04)\end{array}$ & $\begin{array}{c}21 \\
(01 / 05)\end{array}$ \\
\hline $\begin{array}{l}\text { Haemoglobin } \\
(g / d l)\end{array}$ & $12.0-15.0$ & 14.5 & 14.3 & 13.4 & 14.0 & 14.5 & 13.4 & 9.1 \\
\hline $\begin{array}{l}\text { White cells } \\
\left(\times 10^{3} / \mu l\right)\end{array}$ & $4.5-11.0$ & 11.89 & 12.89 & 7.12 & 7.46 & 17.29 & 32.50 & 29.16 \\
\hline
\end{tabular}

Differential count $(\times 103 / \mu l)$

\begin{tabular}{|c|c|c|c|c|c|c|c|c|}
\hline Neutrophils & $2.0-7.5$ & 9.65 & 10.42 & 4.81 & 5.52 & 14.89 & 29.28 & 31.23 \\
\hline Lymphocytes & $1.5-4.0$ & 1.00 & 0.88 & 1.40 & 1.10 & 1.12 & 1.11 & 0.90 \\
\hline Monocytes & $0.2-0.8$ & 1.14 & 1.37 & 0.79 & 0.72 & 1.07 & 1.63 & 1.47 \\
\hline Eosinophils & $0.04-0.40$ & 0.01 & 0.12 & 0.04 & 0.02 & 0.00 & 0.03 & 0.00 \\
\hline $\begin{array}{l}\text { Platelets } \\
(\times 103 / \mu l)\end{array}$ & $150.0-400.0$ & 104 & 100 & 145 & 202 & 138 & 120 & 124 \\
\hline $\begin{array}{l}\text { Creatinine } \\
(\mathrm{mg} / \mathrm{dl})\end{array}$ & $0.66-1.09$ & 1.04 & 1.10 & 1.07 & 1.03 & 2.19 & 3.75 & 7.22 \\
\hline $\begin{array}{l}\text { Bilirubin total } \\
\text { (mg/dl) }\end{array}$ & $0.3-1.2$ & 2.20 & 1.50 & 0.60 & 0.60 & 1.10 & 0.90 & 0.80 \\
\hline $\begin{array}{l}\text { Aspartate transaminase } \\
\text { (IU/I) }\end{array}$ & $10-31$ & 118 & 57 & 28 & 27 & 220 & 123 & 75 \\
\hline $\begin{array}{l}\text { Alanine transaminase } \\
\text { (IU/I) }\end{array}$ & $10-31$ & 30 & 20 & 12 & $<10$ & 29 & 21 & 16 \\
\hline $\begin{array}{l}\text { Gamma- glutamyltransferase } \\
\text { (IU/I) }\end{array}$ & $7-32$ & & & 113 & 108 & 113 & 123 & \\
\hline $\begin{array}{l}\text { Alkaline phosphatase } \\
\text { (IU/I) }\end{array}$ & $30-120$ & & & 77 & 78 & 70 & 80 & \\
\hline $\begin{array}{l}\text { Lactate dehydrogenase } \\
\text { (IU/I) }\end{array}$ & $135-225$ & 690 & & 325 & & & 2738 & \\
\hline $\begin{array}{l}\text { Creatine kinase } \\
\text { (IU/I) }\end{array}$ & $<149$ & & & 39 & & & 48 & \\
\hline $\begin{array}{l}\text { C-reactive protein } \\
(m g / l)\end{array}$ & $<5.0$ & 160.8 & 147.0 & 30.8 & 34.3 & 125.3 & 276.3 & 289.7 \\
\hline $\begin{array}{l}\text { Procalcitonin } \\
\text { (ng/ml) }\end{array}$ & $<0.5$ & & & & & & 6.05 & \\
\hline
\end{tabular}

Table 1. Laboratory data

\section{REFERENCES}

1. Kirchhof P, Benussi S, Kotecha D, Ahlsson A, Atar D, Casadei B, et al. 2016 ESC Guidelines for the management of atrial fibrillation developed in collaboration with EACTS Eur Heart J 2016;37(38):2893--2962.

2. Kamel H, Okin PM, Elkind MSV, ladecola C. Atrial fibrillation and mechanisms of stroke: time for a new model. Stroke 2016;47(3):895-900.

3. Helms J, Tacquard C, Severac F, Leonard-Lorant I, Ohana M, Delabranche X. High risk of thrombosis in patients in severe SARS-CoV-2 infection: a multicenter prospective cohort study. Intensive Care Med 2020;4;1-10.

4. Zhou F, Yu T, Du R, Fan G, Liu Y, Liu Z, et al. Clinical course and risk factors for mortality of adult inpatients with COVID-19 in Wuhan, China: a retrospective cohort study. Lancet 2020;395(10229):1054-1062. 